\title{
Investigating the Clitellata (Annelida) of Icelandic springs with alternative barcodes
}

\author{
Mårten J. Klinth', Agnes-Katharina Kreiling ${ }^{2}$ and Christer Erséus'
}

\begin{abstract}
Klinth MJ, Kreiling A-K and Erséus C. 2019. Investigating the Clitellata (Annelida) of Icelandic springs with alternative barcodes. Fauna norvegica 39: 119-132.
\end{abstract}

DNA barcoding is an invaluable tool to identify clitellates, regardless of life stage or cryptic morphology. However, as COI (the standard barcode for animals) is relatively long (658 bp), sequencing it requires DNA of high quality. When DNA is fragmented due to degradation, alternative barcodes of shorter length present an option to obtain genetic material. We attempted to sequence 187 clitellates sampled from springs in Iceland. However, the material had been stored at room temperature for two years, and DNA of the worms had degraded, and only three COI sequences were produced (i.e., $<2 \%$ success rate). Using two alternative barcodes of $16 \mathrm{~S}$ (one ca. $320 \mathrm{bp}$, the other ca. $70 \mathrm{bp}$ long) we increased the number of sequenced specimens to 51 . Comparisons of the $16 \mathrm{~S}$ sequences showed that even the short $70 \mathrm{bp}$ fragment contained enough genetic variation to separate all clitellate species in the material. Combined with morphological examinations we recognized a total of 23 species, where at least 8 are new records for Iceland, some belonging to genera new for Iceland: Cernosvitoviella and Pristina. All the new taxa are included in an updated species list of Icelandic Clitellata. The material revealed some stygophilic species previously known to inhabit springs, but true stygobionts, which are restricted to groundwater habitats, were not found. Our study shows that short $16 \mathrm{~S}$ fragments can be obtained from DNA too degraded to be used in traditional COI barcoding, and contain enough genetic variation to separate closely related clitellate species.

doi: 10.5324/fn.v39i0.3043. Received: 2019-05-02. Accepted: 2019-09-22. Published online: 2019-11-14. ISSN: 1891-5396 (electronic).

Keywords: Iceland, Oligochaeta, DNA barcodes, 16S, spring fauna

1. Department of Biological \& Environmental Sciences, University of Gothenburg, P.O. Box 463, SE-405 30 Gothenburg, Sweden.

2. Department of Aquaculture and Fish Biology, Hólar University College, Háeyri 1, IS-550 Sauðárkrókur, Iceland.

Corresponding author: Mårten J. Klinth

E-mail:marten.klinth@bioenv.gu.se

\section{INTRODUCTION}

The clitellate fauna ("oligochaetes" and leeches) of Iceland was early on studied by Černosvitov $(1929,1931,1936)$ and Nielsen \& Christensen (1959), but also more specifically reviewed by Bruun (1938a, 1938b) for Hirudinea, Backlund (1949) for Lumbricidae, Hrabě (1952) for Lumbriculidae and Naididae (including the former Tubificidae), Christensen (1962) and Nurminen (1973) for Enchytraeidae, and Erséus (1976) for marine Enchytraeidae and Naididae. Since then, a few additional species have been reported in scattered publications on either pure taxonomy or more general biological issues, such as parasitology (for marine leeches) or ecology; for references, see updated species list for Iceland below. The previous studies report clitellates mainly from soils, lakes, rivers and seashores, but not from freshwater springs, which are the focus of this study.

Springs represent ecotones between groundwater and surface water and give rise to specialized invertebrate communities. On the European mainland, groundwater 
clitellates are rather well known, with many species endemic to various regions (e.g., Sambugar et al. 1999; Giani et al. 2001, 2011; Achurra \& Rodriguez 2008; Bojková et al. 2011; Martin et al. 2015). Groundwater and spring invertebrate communities in Iceland were recently investigated by Govoni et al. (2018) and Kreiling et al. (2018), but these studies focused on insects and crustaceans and the clitellate diversity in Icelandic springs has until now been largely unknown.

In the present study, we examined clitellates collected as a part of a survey on invertebrate fauna in freshwater springs around Iceland. With the intent to save time, we decided to identify the material primarily using molecular data rather than by traditional morphological examination; and to our knowledge, there have not been any published studies of clitellates from Iceland containing genetic sequences, to this date. DNA barcoding (e.g., Hebert et al. 2003, 2004) would allow us to identify juvenile specimens and possible cryptic species. We would then corroborate the identity of the successfully sequenced specimens also by morphological observations. Although this procedure did not work exactly as first intended, the aim to present all the identified species from the springs will still be achieved in this paper. We will also provide an updated list of all species of Clitellata known from Iceland.

\section{MATERIAL AND METHODS}

Worms were collected from 31 springs during the summer of 2015 as a part of a broader study on spring invertebrates in Iceland (Kreiling et al. in prep.). A Surber sampler $\left(0.093 \mathrm{~m}^{2}\right)$ with $63 \mu \mathrm{m}$ mesh size was used for collection of clitellates in the benthic substrate of the spring, and electrobugging (Lento \& Morin 2014, Kreiling et al. 2018) was used for collection of invertebrates in the spring source. The clitellates were stored in $96 \%$ ethanol at room temperature $\left(20^{\circ} \mathrm{C}\right)$ for about two years before further processing. As described below, identification to species level was unsuccessful for a part of the collection, and in the end, the results of the study were based on material from only 19 of the freshwater springs (Figure 1; Table 1).

The clitellate specimens were first examined under a stereomicroscope and the amputated posterior ends of 187 specimens were used for DNA extraction using the QuickExtract DNA Extraction Solution 1.0 (Epicentre, Madison, WI, USA), following the manufacturer's instructions.

The original idea was to barcode all selected specimens using the standard animal barcode COI (cytochrome $c$ oxidase subunit I). However, the DNA proved to have deteriorated considerably (probably due to prolonged storage at room temperature, possibly in too low alcohol concentration), as we were unable to obtain $\mathrm{COI}$ sequences for a vast majority of the

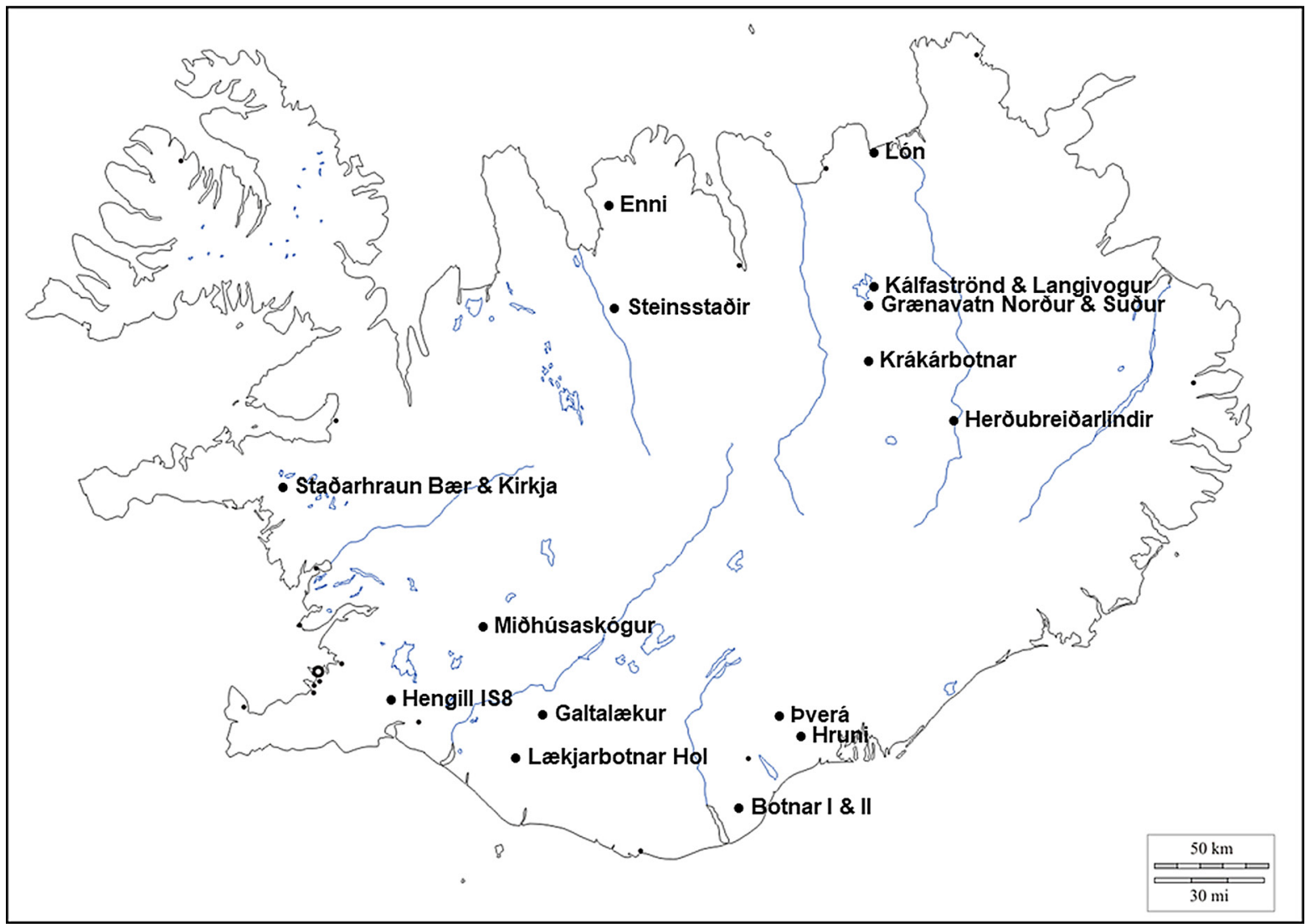

Figure I. Map of the 19 freshwater springs in Iceland from which clitellata have been collected and successfully sequenced in this study. 
Table I. List of the sampling locations with habitat description and some abiotic measurements. Spring names refer either to the name of the water body (stream or lake), or to the surrounding area, or the closest farm. Limnocrene (L) springs form pools of standing water, whereas rheocrene $(\mathrm{R})$ springs originate streams. Elev. = Elevation, O.S. = Oxygen Saturation.

\begin{tabular}{|c|c|c|c|c|c|c|c|}
\hline Spring (type) & Habitat & $\begin{array}{l}\text { Latitude } \\
\text { Longitude } \\
\text { (WGS84) }\end{array}$ & $\begin{array}{l}\text { Elev. } \\
{[\mathrm{m}]}\end{array}$ & Sampling date & $\begin{array}{l}\text { Water } \\
\text { temp. } \\
{\left[{ }^{\circ} \mathrm{C}\right]}\end{array}$ & $\mathrm{pH}$ & $\begin{array}{l}\text { O.S. } \\
{[\%]}\end{array}$ \\
\hline $\begin{array}{l}\text { Botnar I (R) } \\
\text { SE Iceland }\end{array}$ & $\begin{array}{l}\text { Gushing, shallow spring at the edge } \\
\text { of lava field; fine sand }\end{array}$ & $\begin{array}{l}63^{\circ} 38.707^{\prime} \mathrm{N} \\
018^{\circ} 14.749^{\prime} \mathrm{W}\end{array}$ & 36 & 10 July 2015 & 5.6 & 8.0 & 74.2 \\
\hline $\begin{array}{l}\text { Botnar II (L) } \\
\text { SE Iceland }\end{array}$ & $\begin{array}{l}\text { Spring emerging from lava field; low } \\
\text { primary production; fine sand }\end{array}$ & $\begin{array}{l}63^{\circ} 39.275^{\prime} \mathrm{N} \\
018^{\circ} 15.142^{\prime} \mathrm{W}\end{array}$ & 33 & 10 July 2015 & 7.4 & 7.9 & 78.2 \\
\hline $\begin{array}{l}\text { Enni (R) } \\
\text { NW Iceland }\end{array}$ & $\begin{array}{l}\text { Spring forming a small stream on a } \\
\text { grassy hillslope; sand }\end{array}$ & $\begin{array}{l}65^{\circ} 53.371 \mathrm{~N} \\
019^{\circ} 19.755^{\prime} \mathrm{W}\end{array}$ & 151 & $\begin{array}{l}19 \text { September } \\
2015\end{array}$ & 4.5 & 7.3 & 75.9 \\
\hline $\begin{array}{l}\text { Galtalækur (R) } \\
\text { S Iceland }\end{array}$ & $\begin{array}{l}\text { Spring forming a small stream } \\
\text { in wooded area; high density of } \\
\text { surrounding vegetation (grasses, } \\
\text { shrubs and trees); gravel }\end{array}$ & $\begin{array}{l}64^{\circ} 00.453^{\prime} \mathrm{N} \\
019^{\circ} 55.148^{\prime} \mathrm{W}\end{array}$ & 128 & 8 July 2015 & 5.1 & 7.9 & 72.3 \\
\hline $\begin{array}{l}\text { Grænavatn Norður (L) } \\
\text { NE Iceland }\end{array}$ & Spring on lake shore; gravel and mud & $\begin{array}{l}65^{\circ} 32.905^{\circ} \mathrm{N} \\
016^{\circ} 58.908^{`} \mathrm{~W}\end{array}$ & 291 & 22 July 2015 & 6.5 & 8.9 & 60.6 \\
\hline $\begin{array}{l}\text { Grænavatn Suður (L) } \\
\text { NE Iceland }\end{array}$ & $\begin{array}{l}\text { Spring on lake shore; high primary } \\
\text { production; lava rock }\end{array}$ & $\begin{array}{l}65^{\circ} 32.205^{\prime} \mathrm{N} \\
017^{\circ} 00.477^{\prime} \mathrm{W}\end{array}$ & 285 & 22 July 2015 & 4.5 & 9.0 & 63.3 \\
\hline $\begin{array}{l}\text { Hengill IS8 (R) } \\
\text { S Iceland }\end{array}$ & $\begin{array}{l}\text { Hot spring forming a stream in } \\
\text { geothermal area; high primary } \\
\text { production; rock }\end{array}$ & $\begin{array}{l}64^{\circ} 03.414^{\circ} \mathrm{N} \\
021^{\circ} 18.439^{\circ} \mathrm{W}\end{array}$ & 381 & 13 July 2015 & 16.6 & 7.5 & 66.1 \\
\hline $\begin{array}{l}\text { Herðubreiðarlindir (L) } \\
\text { Central Highlands }\end{array}$ & $\begin{array}{l}\text { Big spring in the Central Highlands, } \\
\text { forming a deep stream; high density } \\
\text { of surrounding vegetation (grasses } \\
\text { and shrubs); fine sand }\end{array}$ & $\begin{array}{l}65^{\circ} 11.548^{\prime} \mathrm{N} \\
016^{\circ} 13.508^{\prime} \mathrm{W}\end{array}$ & 493 & 16 August 2015 & 5.9 & 6.8 & 65.6 \\
\hline $\begin{array}{l}\text { Hruni (L) } \\
\text { SE Iceland }\end{array}$ & $\begin{array}{l}\text { Spring in a garden pond; mud and } \\
\text { gravel }\end{array}$ & $\begin{array}{l}63^{\circ} 51.547^{\prime} \mathrm{N} \\
017^{\circ} 44.486^{\prime} \mathrm{W}\end{array}$ & 43 & 11 July 2015 & 3.5 & 7.9 & 75.8 \\
\hline $\begin{array}{l}\text { Kálfaströnd (L) } \\
\text { NE Iceland }\end{array}$ & $\begin{array}{l}\text { Spring on lake shore; lava rock and } \\
\text { sand }\end{array}$ & $\begin{array}{l}65^{\circ} 33.759^{\prime} \mathrm{N} \\
016^{\circ} 56.710^{\prime} \mathrm{W}\end{array}$ & 283 & 21 July 2015 & 5.1 & 9.2 & 54.0 \\
\hline $\begin{array}{l}\text { Krákárbotnar (R) } \\
\text { Central Highlands }\end{array}$ & $\begin{array}{l}\text { Small, isolated spring in the } \\
\text { Central Highlands with almost no } \\
\text { surrounding vegetation; sand }\end{array}$ & $\begin{array}{l}65^{\circ} 19.852^{\prime} \mathrm{N} \\
017^{\circ} 04.654^{\prime} \mathrm{W}\end{array}$ & 430 & 26 July 2015 & 8.6 & 8.8 & 69.5 \\
\hline $\begin{array}{l}\text { Langivogur (L) } \\
\text { NE Iceland }\end{array}$ & $\begin{array}{l}\text { Hot spring at lake shore; high primary } \\
\text { production; lava rock }\end{array}$ & $\begin{array}{l}65^{\circ} 37.012^{\prime} \mathrm{N} \\
016^{\circ} 55.000^{\prime} \mathrm{W}\end{array}$ & 286 & 23 July 2015 & 19.8 & 8.3 & 75.1 \\
\hline $\begin{array}{l}\text { Lón (L) } \\
\text { NE Iceland }\end{array}$ & $\begin{array}{l}\text { Spring at the shore of a shallow } \\
\text { lagoon; lava rock }\end{array}$ & $\begin{array}{l}66^{\circ} 05.785^{\prime} \mathrm{N} \\
016^{\circ} 55.514^{\prime} \mathrm{W}\end{array}$ & 6 & 24 July 2015 & 4.9 & 8.0 & 77.8 \\
\hline $\begin{array}{l}\text { Lækjarbotnar Hol (R) } \\
\text { S Iceland }\end{array}$ & $\begin{array}{l}\text { Spring forming a small stream on } \\
\text { meadow; high density of surrounding } \\
\text { vegetation (grasses); lava rock and } \\
\text { sand }\end{array}$ & $\begin{array}{l}63^{\circ} 57.422^{\prime} \mathrm{N} \\
020^{\circ} 15.892^{\prime} \mathrm{W}\end{array}$ & 78 & 8 July 2015 & 5.5 & 7.9 & 75.6 \\
\hline $\begin{array}{l}\text { Miðhúsaskógur (L) } \\
\text { S Iceland }\end{array}$ & $\begin{array}{l}\text { Spring at the shore of shallow pond; } \\
\text { low primary production; fine sand } \\
\text { and lava rock }\end{array}$ & $\begin{array}{l}64^{\circ} 17.373^{\prime} \mathrm{N} \\
020^{\circ} 30.706^{\prime} \mathrm{W}\end{array}$ & 184 & 8 July 2015 & 2.4 & 9.3 & 78.1 \\
\hline $\begin{array}{l}\text { Staðarhraun Bær (R) } \\
\text { W Iceland }\end{array}$ & $\begin{array}{l}\text { Spring at the edge of lava field, form- } \\
\text { ing a small stream; lava rock and } \\
\text { gravel }\end{array}$ & $\begin{array}{l}64^{\circ} 44.610^{\prime} \mathrm{N} \\
022^{\circ} 05.647^{\prime} \mathrm{W}\end{array}$ & 62 & 28 July 2015 & 5.1 & 5.3 & 79.0 \\
\hline $\begin{array}{l}\text { Staðarhraun Kirkja (R) } \\
\text { W Iceland }\end{array}$ & $\begin{array}{l}\text { Spring at the edge of lava field; sand } \\
\text { and lava rock }\end{array}$ & $\begin{array}{l}64^{\circ} 44.855^{\prime} \mathrm{N} \\
022^{\circ} 05.812^{\prime} \mathrm{W}\end{array}$ & 62 & 28 July 2015 & 4.6 & 5.3 & 79.2 \\
\hline $\begin{array}{l}\text { Steinsstaðir (R) } \\
\text { NW Iceland }\end{array}$ & $\begin{array}{l}\text { Hot spring forming a small stream; } \\
\text { high primary production; sand and } \\
\text { mud }\end{array}$ & $\begin{array}{l}65^{\circ} 28.162^{\prime} \mathrm{N} \\
019^{\circ} 21.390^{\prime} \mathrm{W}\end{array}$ & 62 & 4 August 2015 & 40.24 & 8.47 & 86.3 \\
\hline $\begin{array}{l}\text { Pverá (L) } \\
\text { SE Iceland }\end{array}$ & Spring in shallow pond; sand & $\begin{array}{l}63^{\circ} 52.396^{\prime} \mathrm{N} \\
017^{\circ} 49.199^{\prime} \mathrm{W}\end{array}$ & 53 & 11 July 2015 & 5.1 & 7.5 & 76.1 \\
\hline
\end{tabular}


specimens. Additionally, as most worms were tiny the DNA samples as such were small. DNA is known to degrade faster when stored at room temperature rather than in a freezer (Vink et al. 2005), but old fragmented DNA can still be amplified by using primers that target a shorter gene fragment (Hajibabaei et al. 2006). There is an alternative reverse primer developed for naidid clitellates (COI-E, Bely \& Wray 2004), but as it targets the same sequence length as the primers we used (Folmer et al. 1994) we reasoned it would not handle fragmented DNA better and thus did not use it. A number of universal primers have been developed targeting shorter fragments of the COI gene, to manage degraded DNA mainly in metabarcoding studies (Meusiner et al. 2008, Leray et al. 2013). However, said primers have only been tested for a limited number of annelids and the universality of some has been questioned (Arif et al. 2011). As an alternative, mitochondrial 16S rDNA has been suggested as a more favourable option, particularly for metabarcoding, since this gene's highly conserved sites make it easy to develop universal primers (Deagle et al. 2014). As we have an interest in the potential for metabarcoding of clitellates we decided to try two shorter gene fragments of $16 \mathrm{~S}$.

PCRs were run for all specimens using Red Taq DNA Polymerase Master Mix (VWR, Haasrode, Belgium) in 25 $\mu \mathrm{L}$ reactions, with the three primer pairs in Table 2 . The PCR products were examined using electrophoresis on an agarose gel and the successful samples were purified using exonuclease I and FastAP thermosensitive alkaline phosphatase. The purified products were sequenced by MWG Eurofins Operon (Edersberg, Germany), and the resulting trace files were assembled in Geneious 6.1.8 (Drummond et al. 2011). The successful sequences were compared to data in the Barcoding of Life Database (BOLD) and GenBank (NCBI), in order to recognize barcode clusters representing putative species, and to genetically identify the specimens to species.

We also compared the sequences of the two $16 \mathrm{~S}$ barcodes (one ca. $320 \mathrm{bp}$, the other ca. $70 \mathrm{bp}$ long), by alignment and Neighbor-Joining (NJ) analyses in Geneious. The COI and longer $16 \mathrm{~S}$ sequences were later uploaded to Genbank, the shorter $16 \mathrm{~S}$ sequences are provided in the text below.

The vouchers (anterior ends) of 181 specimens, i.e., excluding most earthworms (Lumbricidae), were stained in paracarmine, dehydrated in xylene and mounted in Canada balsam on microscope slides following Erséus (1994). The vouchers of specimens identified to species, or in some cases generic, level were deposited in the Swedish Museum of Natural History (SMNH) and they are listed in Table 3. Reference specimens were also included to aid in the identification of two species with only immature specimens, whose barcodes could not be matched with anything in the public databases: CE19501 Fridericia dura, collected in Kristiansund, Möre og Romsdal, Norway, 63.1258 N, 7.7352 E by Christer Erséus, 13 Aug 2013, and CE22027 Marionina cf. argentea, collected in Nedrehus, Maurangerfjorden, Kvinnherad, Hordaland, Norway, 60.1295 N, 6.3146 E by Christer Erséus \& Mårten Klinth, 14 May 2014, both deposited in the University Museum of Bergen (ZMBN) (Table 3).

\section{RESULTS}

It soon became apparent that the DNA of the samples had degraded substantially, as we obtained successful COI sequences from only three of the 187 selected worms. They were genetically identified as Bimastos rubidus (Savigny, 1826) sensu lato, Cernosvitoviella pusilla Nurminen, 1973, and Chaetogaster cf. diastrophus (Gruithuisen, 1828), respectively (Table 3).

The longer (320 bp) of the two $16 \mathrm{~S}$ barcodes was more successful than the COI barcode, but we still only got results for 54 specimens. Moreover, after examination of the microscope slides, the morphology did not agree with the DNA results for eight of these 54 worms, most likely due to DNA contamination, leaving only 46 individuals confidently identified by both DNA and morphology (Table 3 specifies how each specimen was identified).

Table 2. Primers and PCR programs used to sequence COI and $16 \mathrm{~S}$.

\begin{tabular}{|c|c|c|c|}
\hline Target & Primers & PCR program & Reference \\
\hline $\begin{array}{l}\text { COI } \\
658 \text { bp }\end{array}$ & $\begin{array}{l}\text { LCO1490 (forward) } \\
\text { GGTCAACAAATCATAAAGATATTGG } \\
\text { HCO2198 (reverse) } \\
\text { TAAACTTCAGGGTGACCAAAAAATCA }\end{array}$ & $\begin{array}{l}95^{\circ} \mathrm{C} 5 \mathrm{~min},\left(35 \text { cycles of } 95^{\circ} \mathrm{C} 40 \mathrm{~s},\right. \\
\left.45^{\circ} \mathrm{C} 45 \mathrm{~s} 72^{\circ} \mathrm{C} 1 \mathrm{~min}\right), 72^{\circ} \mathrm{C} 8 \mathrm{~min}\end{array}$ & (Folmer et al. 1994) \\
\hline $\begin{array}{l}16 \mathrm{~S} \\
\text { ca. } 320 \mathrm{bp}\end{array}$ & $\begin{array}{l}\text { Ann16SF (forward) } \\
\text { GCGGTATCCTGACCGTRCWAAGGTA } \\
\text { Ann16SR (reverse) } \\
\text { TCCTAAGCCAACATCGAGGTGCCAA }\end{array}$ & $\begin{array}{l}95^{\circ} \mathrm{C} 5 \mathrm{~min},\left(35 \text { cycles of } 95^{\circ} \mathrm{C} 30 \mathrm{~s},\right. \\
\left.50^{\circ} \mathrm{C} 30 \mathrm{~s} 72^{\circ} \mathrm{C} 1 \mathrm{~min}\right), 72^{\circ} \mathrm{C} 8 \mathrm{~min}\end{array}$ & (Sjölin et al. 2005) \\
\hline $\begin{array}{l}16 \mathrm{~S} \\
\text { ca. } 70 \mathrm{bp}\end{array}$ & $\begin{array}{l}\text { ewD (forward) } \\
\text { ATTCGGTTGGGGCGACC } \\
\text { ewE (reverse) } \\
\text { CTGTTATCCCTAAGGTAGCTT }\end{array}$ & $\begin{array}{l}95^{\circ} \mathrm{C} 5 \mathrm{~min},\left(35 \text { cycles of } 95^{\circ} \mathrm{C} 30 \mathrm{~s},\right. \\
\left.58^{\circ} \mathrm{C} 30 \mathrm{~s} 72^{\circ} \mathrm{C} 10 \mathrm{~s}\right), 72^{\circ} \mathrm{C} 5 \mathrm{~min}\end{array}$ & (Bienert et al. 2012) \\
\hline
\end{tabular}


Table 3. List of Icelandic specimens used in this study with specimen ID's (identification numbers), identification method (B = BOLD; G $=$ Genbank; $\mathrm{M}=$ morphology; $\mathrm{R}$ = based on match to other non-Icelandic reference material, presented at the end of the table, and with sampling sites specified in material and methods), the spring in which they were collected, Genbank accession numbers and museum voucher ID's. We only deposited the longer $16 \mathrm{~S}$ fragment. Sequences from the shorter $16 \mathrm{~S}$ fragment are presented in the text of the Results. More detailed description of the springs in Table 1.

\begin{tabular}{|c|c|c|c|c|c|c|}
\hline \multirow{2}{*}{$\begin{array}{l}\text { Taxon } \\
\text { (Identification method) }\end{array}$} & \multirow{2}{*}{$\begin{array}{l}\text { Specimen } \\
\text { ID }\end{array}$} & \multirow[t]{2}{*}{ Spring locality } & \multicolumn{3}{|c|}{ Genbank acc. no. } & \multirow[t]{2}{*}{ Voucher ID } \\
\hline & & & $\mathrm{COI}$ & $16 \mathrm{~S}(320 \mathrm{bp})$ & $16 \mathrm{~S}(70 \mathrm{bp})$ & \\
\hline \multicolumn{7}{|l|}{ Enchytraeidae } \\
\hline $\begin{array}{l}\text { Cernosvitoviella } \\
\text { aggtelekiensis Dózsa-Farkas, } \\
1970(\mathrm{GM})\end{array}$ & CE30974 & Hruni & & MK837025 & & $\begin{array}{l}\text { SMNH } \\
176517\end{array}$ \\
\hline $\begin{array}{l}\text { Cernosvitoviella cf. minor } \\
\text { Dózsa-Farkas, } 1990 \text { (GM) }\end{array}$ & CE31592 & Hruni & & & $\begin{array}{l}\text { Sequence in } \\
\text { Results }\end{array}$ & $\begin{array}{l}\text { SMNH } \\
176518\end{array}$ \\
\hline $\begin{array}{l}\text { Cernosvitoviella pusilla } \\
\text { Nurminen, } 1973 \text { (M) }\end{array}$ & CE30979 & Botnar II & & MK837026 & (Overlapping) & $\begin{array}{l}\text { SMNH } \\
176519\end{array}$ \\
\hline $\begin{array}{l}\text { Cernosvitoviella pusilla } \\
\text { Nurminen, } 1973 \text { (B) }\end{array}$ & CE31607 & Staðarhraun Bær & MK837024 & MK837027 & (Overlapping) & $\begin{array}{l}\text { SMNH } \\
176520\end{array}$ \\
\hline $\begin{array}{l}\text { Cognettia varisetosa } \\
\text { (Martinsson, Rota \& Erséus, } \\
\text { 2015) (M) }\end{array}$ & CE30958 & Enni & & & & $\begin{array}{l}\text { SMNH } \\
176522\end{array}$ \\
\hline $\begin{array}{l}\text { Enchytraeus buchholzi } 1 \\
\text { Vejdovský, } 1879(\mathrm{M})\end{array}$ & CE30973 & Hruni & & MK837028 & (Overlapping) & $\begin{array}{l}\text { SMNH } \\
176523\end{array}$ \\
\hline $\begin{array}{l}\text { Enchytraeus buchholzi } 1 \\
\text { Vejdovský, } 1879\end{array}$ & CE31564 & Botnar I & & & $\begin{array}{l}\text { Sequence in } \\
\text { Results }\end{array}$ & $\begin{array}{l}\text { SMNH } \\
176524\end{array}$ \\
\hline $\begin{array}{l}\text { Enchytraeus buchholzi } 2 \\
\text { Vejdovský, } 1879(\mathrm{M})\end{array}$ & CE31504 & Langivogur & & MK837029 & & $\begin{array}{l}\text { SMNH } \\
176525\end{array}$ \\
\hline $\begin{array}{l}\text { Fridericia dura (Eisen, 1879) } \\
\text { (R) }\end{array}$ & CE30963 & Krákárbotnar & & MK837030 & (Overlapping) & $\begin{array}{l}\text { SMNH } \\
176526\end{array}$ \\
\hline $\begin{array}{l}\text { Henlea perpusilla Friend, } \\
1911(\mathrm{G})\end{array}$ & CE30978 & Botnar II & & MK837031 & (Overlapping) & $\begin{array}{l}\text { SMNH } \\
176527\end{array}$ \\
\hline $\begin{array}{l}\text { Lumbricillus arenarius } \\
\text { (Michaelsen, 1889) (GM) }\end{array}$ & CE31573 & Herðubreiðarlindir & & MK837032 & & $\begin{array}{l}\text { SMNH } \\
176528\end{array}$ \\
\hline $\begin{array}{l}\text { Lumbricillus arenarius } \\
\text { (Michaelsen, 1889) (GM) }\end{array}$ & CE31575 & Herðubreiðarlindir & & MK837033 & & $\begin{array}{l}\text { SMNH } \\
176529\end{array}$ \\
\hline $\begin{array}{l}\text { Lumbricillus arenarius } \\
\text { (Michaelsen, 1889) (GM) }\end{array}$ & CE31577 & Herðubreiðarlindir & & MK837034 & (Overlapping) & $\begin{array}{l}\text { SMNH } \\
176530\end{array}$ \\
\hline $\begin{array}{l}\text { Marionina cf. argentea } \\
\text { (Michaelsen, 1889) (R) }\end{array}$ & CE31590 & Pverá & & MK837035 & & $\begin{array}{l}\text { SMNH } \\
176531\end{array}$ \\
\hline Marionina sp. & CE31579 & Herðubreiðarlindir & & MK837036 & & $\begin{array}{l}\text { SMNH } \\
176532\end{array}$ \\
\hline Marionina sp. & CE31580 & Herðubreiðarlindir & & MK837037 & & $\begin{array}{l}\text { SMNH } \\
176533\end{array}$ \\
\hline Marionina sp. & CE31583 & Pverá & & MK837038 & & $\begin{array}{l}\text { SMNH } \\
176534\end{array}$ \\
\hline Marionina sp. & CE31587 & Pverá & & MK837039 & & $\begin{array}{l}\text { SMNH } \\
176535\end{array}$ \\
\hline Marionina sp. & CE31589 & Pverá & & MK837040 & & $\begin{array}{l}\text { SMNH } \\
176536\end{array}$ \\
\hline Marionina sp. & CE31603 & Grænavatn Norður & & MK837041 & & $\begin{array}{l}\text { SMNH } \\
176537\end{array}$ \\
\hline $\begin{array}{l}\text { Mesenchytraeus cf. armatus } \\
\text { (Levinsen, 1884) (GM) }\end{array}$ & CE30954 & Miðhúsaskógur & & MK837042 & (Overlapping) & $\begin{array}{l}\text { SMNH } \\
176538\end{array}$ \\
\hline $\begin{array}{l}\text { Mesenchytraeus cf. armatus } \\
\text { (Levinsen, 1884) (GM) }\end{array}$ & CE30968 & Grænavatn Suður & & & $\begin{array}{l}\text { Sequence in } \\
\text { Results }\end{array}$ & $\begin{array}{l}\text { SMNH } \\
176539\end{array}$ \\
\hline $\begin{array}{l}\text { Mesenchytraeus cf. armatus } \\
\text { (Levinsen, 1884) (GM) }\end{array}$ & CE30972 & Hruni & & MK837043 & (Overlapping) & $\begin{array}{l}\text { SMNH } \\
176540\end{array}$ \\
\hline
\end{tabular}


Table 3. Continued.

\begin{tabular}{|c|c|c|c|c|c|c|}
\hline \multirow{2}{*}{$\begin{array}{l}\text { Taxon } \\
\text { (Identification method) }\end{array}$} & \multirow{2}{*}{$\begin{array}{l}\text { Specimen } \\
\text { ID }\end{array}$} & \multirow[t]{2}{*}{ Spring locality } & \multicolumn{3}{|c|}{ Genbank acc. no. } & \multirow[t]{2}{*}{ Voucher ID } \\
\hline & & & $\mathrm{COI}$ & $16 \mathrm{~S}(320 \mathrm{bp})$ & $16 \mathrm{~S}(70 \mathrm{bp})$ & \\
\hline $\begin{array}{l}\text { Mesenchytraeus cf. armatus } \\
\text { (Levinsen, 1884) (GM) }\end{array}$ & CE30986 & Botnar II & & MK837045 & (Overlapping) & $\begin{array}{l}\text { SMNH } \\
176542\end{array}$ \\
\hline \multicolumn{7}{|l|}{ Lumbricidae } \\
\hline $\begin{array}{l}\text { Aporrectodea caliginosa } \\
\text { (Savigny, 1826) }(\mathrm{G})\end{array}$ & CE30987 & Staðarhraun Bær & & MK837046 & (Overlapping) & $\begin{array}{l}\text { SMNH } \\
176543\end{array}$ \\
\hline $\begin{array}{l}\text { Bimastos rubidus s. lat. } \\
\text { (Savigny, 1826) (GB) }\end{array}$ & CE30982 & Botnar II & MK837022 & & $\begin{array}{l}\text { Sequence in } \\
\text { Results }\end{array}$ & $\begin{array}{l}\text { SMNH } \\
176544\end{array}$ \\
\hline $\begin{array}{l}\text { Dendrobaena octaedra } \\
\text { (Savigny, 1826) }(\mathrm{G})\end{array}$ & CE30975 & Steinsstaðir & & & $\begin{array}{l}\text { Sequence in } \\
\text { Results }\end{array}$ & $\begin{array}{l}\text { SMNH } \\
176545\end{array}$ \\
\hline $\begin{array}{l}\text { Dendrobaena octaedra } \\
\text { (Savigny, 1826) }(\mathrm{G})\end{array}$ & CE31506 & Galtalækur & & MK837047 & & $\begin{array}{l}\text { SMNH } \\
176546\end{array}$ \\
\hline $\begin{array}{l}\text { Eiseniella tetraedra (Savigny, } \\
1826)(\mathrm{G})\end{array}$ & CE30950 & Langivogur & & MK837048 & (Overlapping) & $\begin{array}{l}\text { SMNH } \\
176547\end{array}$ \\
\hline \multicolumn{7}{|l|}{ Naididae } \\
\hline $\begin{array}{l}\text { Chaetogaster cf. diastrophus } \\
\text { (Gruithuisen, 1828) (G) }\end{array}$ & CE31491 & Staðarhraun Kirkja & MK837023 & MK837049 & & $\begin{array}{l}\text { SMNH } \\
176548\end{array}$ \\
\hline Chaetogaster sp. $=$ langi $?(\mathrm{M})$ & CE31604 & Grænavatn Norður & & MK837050 & & $\begin{array}{l}\text { SMNH } \\
176549\end{array}$ \\
\hline $\begin{array}{l}\text { Nais communis/variabilis spe- } \\
\text { cies complex, morphotype A3 } \\
\text { (Envall et al. 2012) (G) }\end{array}$ & CE30951 & Langivogur & & MK837051 & & $\begin{array}{l}\text { SMNH } \\
176550\end{array}$ \\
\hline $\begin{array}{l}\text { Nais elinguis Müller, } 1773 \\
(\mathrm{GM})\end{array}$ & CE30948 & Lón & & MK837052 & & $\begin{array}{l}\text { SMNH } \\
176551\end{array}$ \\
\hline $\begin{array}{l}\text { Nais elinguis Müller, } 1773 \\
(\mathrm{GM})\end{array}$ & CE30949 & Lón & & MK837053 & & $\begin{array}{l}\text { SMNH } \\
176552\end{array}$ \\
\hline $\begin{array}{l}\text { Nais elinguis Müller, } 1773 \\
(\mathrm{GM})\end{array}$ & CE30967 & Lækjarbotnar Hol & & MK837054 & & $\begin{array}{l}\text { SMNH } \\
176553\end{array}$ \\
\hline $\begin{array}{l}\text { Nais elinguis Müller, } 1773 \\
(\mathrm{GM})\end{array}$ & CE30971 & Pverá & & MK837055 & & $\begin{array}{l}\text { SMNH } \\
176554\end{array}$ \\
\hline $\begin{array}{l}\text { Nais elinguis Müller, } 1773 \\
(\mathrm{GM})\end{array}$ & CE30980 & Botnar II & & MK837056 & & $\begin{array}{l}\text { SMNH } \\
176555\end{array}$ \\
\hline $\begin{array}{l}\text { Nais elinguis Müller, } 1773 \\
(\mathrm{GM})\end{array}$ & CE30981 & Botnar II & & MK837057 & & $\begin{array}{l}\text { SMNH } \\
176556\end{array}$ \\
\hline $\begin{array}{l}\text { Nais elinguis Müller, } 1773 \\
(\mathrm{GM})\end{array}$ & CE30983 & Botnar II & & MK837058 & & $\begin{array}{l}\text { SMNH } \\
176557\end{array}$ \\
\hline $\begin{array}{l}\text { Nais elinguis Müller, } 1773 \\
(\mathrm{GM})\end{array}$ & CE30984 & Botnar II & & MK837059 & & $\begin{array}{l}\text { SMNH } \\
176558\end{array}$ \\
\hline $\begin{array}{l}\text { Nais elinguis Müller, } 1773 \\
(\mathrm{GM})\end{array}$ & CE30985 & Botnar II & & MK837060 & & $\begin{array}{l}\text { SMNH } \\
176559\end{array}$ \\
\hline $\begin{array}{l}\text { Nais elinguis Müller, } 1773 \\
(\mathrm{GM})\end{array}$ & CE31480 & Kálfaströnd & & MK837061 & & $\begin{array}{l}\text { SMNH } \\
176560\end{array}$ \\
\hline $\begin{array}{l}\text { Nais elinguis Müller, } 1773 \\
(\mathrm{GM})\end{array}$ & CE31493 & Staðarhraun Kirkja & & MK837062 & & $\begin{array}{l}\text { SMNH } \\
176561\end{array}$ \\
\hline $\begin{array}{l}\text { Nais elinguis Müller, } 1773 \\
\text { (GM) }\end{array}$ & CE31581 & Lækjarbotnar Hol & & MK837063 & & $\begin{array}{l}\text { SMNH } \\
176562\end{array}$ \\
\hline $\begin{array}{l}\text { Nais elinguis Müller, } 1773 \\
\text { (GM) }\end{array}$ & CE31582 & Grænavatn Suður & & MK837064 & & $\begin{array}{l}\text { SMNH } \\
176563\end{array}$ \\
\hline $\begin{array}{l}\text { Nais elinguis Müller, } 1773 \\
(\mathrm{GM})\end{array}$ & CE31605 & Staðarhraun Bær & & MK837065 & & $\begin{array}{l}\text { SMNH } \\
176564\end{array}$ \\
\hline $\begin{array}{l}\text { Nais elinguis Müller, } 1773 \\
(\mathrm{GM})\end{array}$ & CE31606 & Staðarhraun Bær & & MK837066 & & $\begin{array}{l}\text { SMNH } \\
176565\end{array}$ \\
\hline $\begin{array}{l}\text { Nais elinguis Müller, } 1773 \\
\text { (GM) }\end{array}$ & CE31619 & Staðarhraun Bær & & MK837068 & & $\begin{array}{l}\text { SMNH } \\
176567\end{array}$ \\
\hline
\end{tabular}


Table 3. Continued.

\begin{tabular}{|c|c|c|c|c|c|c|}
\hline \multirow{2}{*}{$\begin{array}{l}\text { Taxon } \\
\text { (Identification method) }\end{array}$} & \multirow{2}{*}{$\begin{array}{l}\text { Specimen } \\
\text { ID }\end{array}$} & \multirow[t]{2}{*}{ Spring locality } & \multicolumn{3}{|c|}{ Genbank acc. no. } & \multirow[t]{2}{*}{ Voucher ID } \\
\hline & & & $\mathrm{COI}$ & 16S (320 bp) & $16 \mathrm{~S}(70 \mathrm{bp})$ & \\
\hline $\begin{array}{l}\text { Nais elinguis Müller, } 1773 \\
(\mathrm{GM})\end{array}$ & CE31620 & Staðarhraun Bær & & MK837069 & & $\begin{array}{l}\text { SMNH } \\
176568\end{array}$ \\
\hline $\begin{array}{l}\text { Pristina foreli (Piguet, 1907) } \\
\text { (M) }\end{array}$ & $\begin{array}{l}\text { CE30943- } \\
45\end{array}$ & Hengill IS8 & & & & $\begin{array}{l}\text { SMNH } \\
176569\end{array}$ \\
\hline $\begin{array}{l}\text { Tubifex cf. tubifex (Müller, } \\
\text { 1774) }(\mathrm{G})\end{array}$ & CE31560 & Botnar I & & MK837070 & & $\begin{array}{l}\text { SMNH } \\
176570\end{array}$ \\
\hline $\begin{array}{l}\text { Uncinais uncinata (Ørsted, } \\
\text { 1842) (M) }\end{array}$ & CE31593 & Hruni & & & & $\begin{array}{l}\text { SMNH } \\
176571\end{array}$ \\
\hline \multicolumn{7}{|l|}{ Non-Icelandic reference material } \\
\hline $\begin{array}{l}\text { Fridericia dura (Eisen, 1879) } \\
\text { (M) }\end{array}$ & CE19501 & Norway & MN395701 & $\begin{array}{l}\text { MN394410 } \\
(478 \text { bp) }\end{array}$ & & $\begin{array}{l}\text { ZMBN } \\
110172\end{array}$ \\
\hline $\begin{array}{l}\text { Marionina cf. argentea } \\
\text { (Michaelsen, 1889) (M) }\end{array}$ & CE22027 & Norway & MN395702 & $\begin{array}{l}\text { MN394411 } \\
(474 \mathrm{bp})\end{array}$ & & $\begin{array}{l}\text { ZMBN } \\
110740\end{array}$ \\
\hline
\end{tabular}

The shorter $16 \mathrm{~S}$ barcode (70 bp) only produced 17 successful sequences (Table 3), mostly from specimens already successfully barcoded with the longer 16S fragment, increasing the total number of DNA-barcoded (but non-contaminated) specimens to 51 ( $27 \%$ of the original 187 specimens). The sequences of the five specimens that were successfully sequenced only for the shorter 16S fragment (i.e., five sequences not overlapping with our longer 16S uploaded on Genbank) are presented here (note that the sequence for CE31592 is incomplete):

\section{CE31592 Cernosvitoviella cf. minor}

TTGGGGCGACCAAGGAAAAATCATCCTTAATAAAAA AGACATAC;

CE31564 Enchytraeus buchholzi 1

ATTCGGTTGGGGCGACCCAGGATAAATCATCCTGTAA AAAATAGACAAATATGTCAACCATATGAACCTAGTTA GATCACAGATCAAGCTACCTTAGGGATAACAGA; CE30968 Mesenchytraeus cf. armatus

TATTCGGTTGGGGCGACCATGGATAAATCATCCATAA TTTATAAGACAAACTAGTCATTAATAGATCCTTTTAAG ATCACAGAATCAAGCTACCTTAGGGATAACAGA;

\section{CE30982 Dendrodrilus rubidus}

ATTCGGTTGGGGCGACCAGGGAAATAATAAATCATCC CTCATTATAAGATAAATAAATCTCTCCCATGACCCTTG AAAAAGATCAAAAAACCAAGCTACCTTAGGGATAAC AGA;

CE30975 Dendrobaena octaedra

TATTCGGTTGGGGCGACCAGGGAAATTAATAATCATC CCTTAGTCAAAGATTTATTAATCTATAAATAAGACCCT ACTAAGATCTAAAGAACAAGCTACCTTAGGGATAACA GA.

Some worms were thus successfully sequenced only for one or two of the three barcode markers.

In the $\mathrm{NJ}$ analyses, both the $320 \mathrm{bp}$ (Figure 2) and 70 bp (Figure 3) 16S barcodes clustered specimens of the same species, and clearly separated the recognized species from each other.

Among the 51 DNA-barcoded individuals we identified 20 different species, at least six of which are new records for Iceland (Table 4): Cernosvitoviella aggtelekiensis Dózsa-Farkas, 1970, C. cf. minor Dózsa-Farkas, 1990, C. pusilla, Fridericia dura (Eisen, 1879), Mesenchytraeus cf. armatus (Levinsen, 1884), and Chaetogaster cf. diastrophus. Among the barcoded worms, we also found a small specimen of Chaetogaster, which is possibly Ch. langi Bretscher, 1896 (previously known from Iceland; Hrabě 1952), but not yet confidently identified. Its 16S barcode (320 bp) matches a species also found in Sweden, Norway and the Azores (Klinth \& Erséus, unpublished data). The species referred to as Marionina sp. could also potentially be new to Iceland.

In the barcoded material, most species were represented by a single or a few specimens only, except Nais elinguis Müller, 1773, for which we obtained 16S (320 bp) sequences from 18 individuals (Table 3). Some of the other species reported here (Table 3) belong to complexes of closely related, possibly cryptic, species: For the time being, they are identified as the closest name-bearing morpho-species, but may in the future be recognized and described as separate taxa. These taxa are: Enchytraeus buchholzi Vejdovský, 1879 (for which we found two separate species matching the general E. buchholzi morphology, "buchholzi 1" and "2"), Ch cf. diastrophus, Marionina cf. argentea (Michaelsen, 1889), Mesenchytraeus cf. armatus, and Nais communis/variabilis (Piguet, 1906; i.e., we found here morphotype A3 sensu Envall et al. 2012). Moreover, there is still some uncertainty whether the earthworm Bimastos rubidus (Savigny, 1826) should include B. subrubicundus (Eisen, 1874), and B. tenuis (Eisen, 1874), all three of which have been reported from Iceland.

The material that did not produce any molecular data was examined based on morphology and could in most cases only be determined to genus level; such specimens will not be further 


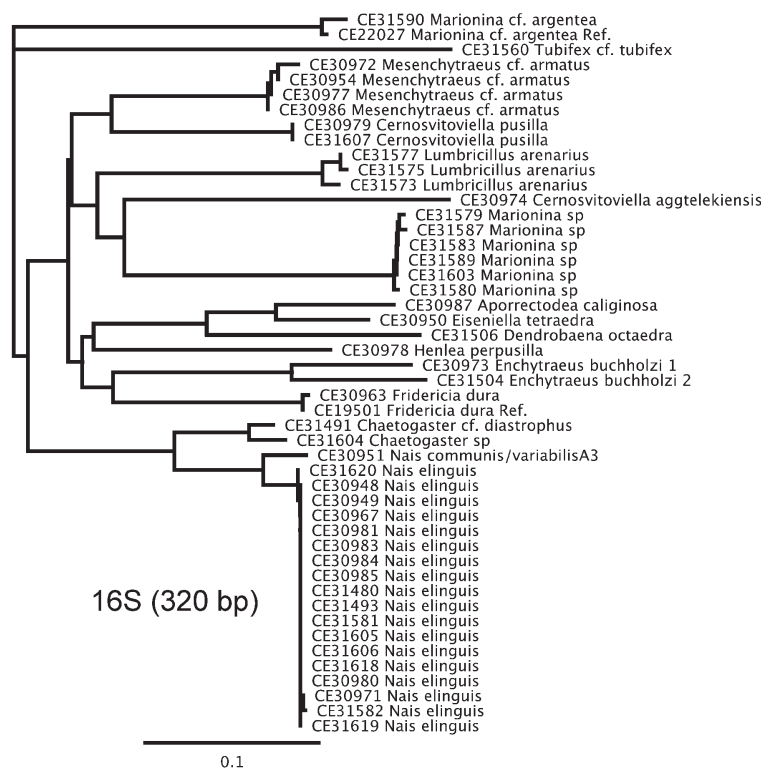

Figure 2. Neighbor-Joining tree for the longer ( $320 \mathrm{bp)} 16 \mathrm{~S}$ barcode of the 46 successfully barcoded specimens and two reference barcodes (Ref.). Scale bar shows $10 \%$ genetic distance under the Jukes-Cantor model. Note that the NJ tree is a poor estimation of actual phylogenetic relationships.

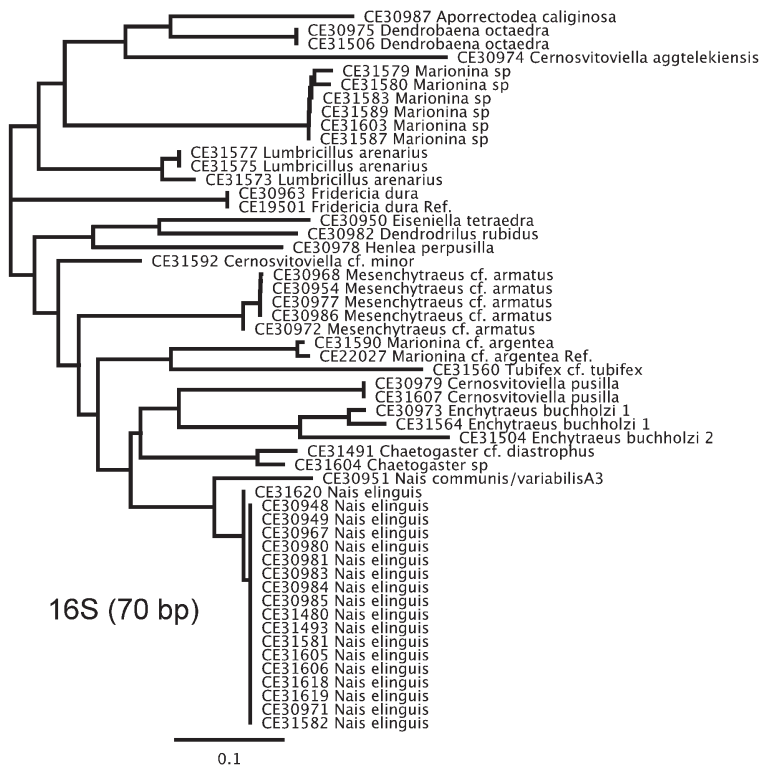

Figure 3. Neighbor-Joining tree for the shorter $(70 \mathrm{bp}) 16 \mathrm{~S}$ barcode of all 51 16S-barcoded specimens and two reference barcodes (Ref.). The alignment is $79 \mathrm{bp}$ long and consists of 17 barcodes sequenced using the specific primers of this shorter fragment (see Table 2), and 36 barcodes from the corresponding section in the longer ( 320 bp) fragment. Scale bar shows $10 \%$ genetic distance under the Jukes-Cantor model. Note that the $\mathrm{NJ}$ tree is a poor estimation of actual phylogenetic relationships. treated here (this is why not all originally sampled springs are shown in Figure 1 and Table 1). However, we did identify a few additional species in our spring material based on morphology alone. One being Cognettia varisetosa (Martinsson, Rota \& Erséus, 2015), earlier regarded as C. glandulosa (previously recorded from Iceland); C. varisetosa is thus, at least nominally, a new record for Iceland. We also found specimens of Pristina foreli (Piguet, 1907), which represents a genus (Pristina Ehrenberg, 1828) never recorded in Iceland before. Finally, we found Uncinais uncinata (Ørsted, 1842), a taxon already known from the country (see Table 4).

In total, we identified 23 species, of which at least 8 are new records to Iceland. These identified species were collected from 19 of the 31 sites sampled.

\section{DISCUSSION}

\section{Clitellates of the Icelandic springs}

The species found in the Icelandic springs are a mixture of Lumbricidae, Enchytraeidae and Naididae. Earthworms (Lumbricidae) are mostly terrestrial, but among our four species found, Eiseniella tetraedra is a characteristic inhabitant of running water or wet soils, and common also in caves and springs, in the Western Palaearctic (Sims \& Gerard 1985). The other three are terrestrial worms "accidently found in water" (Timm 2009, p. 188).

All Enchytraeidae (13 species) and Naididae (7 species) in the studied springs are known also from continental Europe. This conclusion is largely based on molecular data, as we were able to compare the $16 \mathrm{~S}$ barcodes of the Icelandic specimens with the corresponding barcodes of $<400$ species of Enchytraeidae and Naididae from Sweden and Norway (Erséus and Klinth, unpubl.). This enabled us to identify certain (cryptic) forms within the species complexes of some traditional morphospecies (i.e., Cernosvitoviella minor s. lat., Enchytraeus buchholzi s. lat., Marionina argentea s. lat., Chaetogaster diastrophus s. lat., Tubifex tubifex s. lat.) and one small, yet unidentified Chaetogaster species. However, proper binominal names of these cryptic species are not yet established.

Fridericia dura (Enchytraeidae) is typically terrestrial (Dózsa-Farkas 2019), but was found outside its normal habitat in this study. The remaining enchytraeids and all naidids are normally restricted to aquatic or semi-aquatic habitats (Timm 2009; Schmelz \& Collado 2010; Klinth et al. 2017b), and they appear as a somewhat impoverished assemblage of the clitellates typical of streams, rivers, lakes and ponds in other parts of Northern Europe.

Springs are windows into the stygofauna, i.e., stygofaunal species are categorized as those restricted to groundwater (stygobites), those inhabiting both surface and ground waters, or preferring a transition zone of these habitats (stygophiles), and those accidentally or occasionally present in groundwater (stygoxenes). No Icelandic clitellates so far known are 
stygobites. For instance, there are no records of species of the genera typically containing stygobitic (often endemic) taxa in continental Europe, such as Trichodrilus Claparède, 1862 (Lumbriculidae), Aberrantidrilus Martin, 2015, Aktedrilus Knöllner, 1935, Gianius Erséus, 1992, Protuberodrilus Giani \& Martinez-Ansemil, 1979, Rhyacodrilus Bretscher, 1901, and Troglodrilus Juget et al., 2006 (all Naididae). However, five meiobenthic species found in the present study (Cernosvitoviella aggtelekiensis, C. pusilla, C. cf. minor, Marionina cf. argentea and Pristina foreli) are associated with surface waters as well as springs and groundwater in Norway and Sweden, and (when in springs) often in various combinations with each other (Erséus \& Klinth, unpubl.). These taxa may be regarded as stygophiles, and their small size may be advantageous in springs, where nutrient levels are often low. Moreover, three other taxa (Lumbricillus arenarius, Marionina sp. and Nais elinguis) are normally associated with marine, intertidal habitats. Lumbricillus arenarius is also known from a spring in Northern Svalbard (Klinth et al. 2017b), and Nais elinguis is well known from both springs and coastal streams (e.g., Timm 2009), but the unidentified, possibly new species of Marionina was earlier collected only in marine habitats in Norway and Sweden (Erséus \& Klinth, unpubl.).

Enchytraeus buchholzi s. lat., a species complex generally associated with "not too acidic" soils (Schmelz and Collado, 2010), sometimes occurs in freshwater (Timm 2009). The two genetically distinct forms of $E$. buchholzi found in our study are common in wet soils, including springs, in mainland Scandinavia (Erséus \& Klinth, unpubl.). They thus appear to be more aquatic than other members of the complex. As for Tubifex tubifex s. lat., most of the cryptic species studied by us (Erséus \& Klinth), including the one from the (Icelandic) Botnar I spring, are occasionally found in springs of other parts of Northern Europe. To conclude, we consider our recorded Lumbricidae spp. (possibly excepting the somewhat "stygophilic" Eiseniella tetraedra), Enchytraeus buchholzi 1 \& 2, Henlea perpusilla, Mesenchytraeus cf. armatus, T. cf. tubifex, Cognettia varisetosa, Chaetogaster spp. and Uncinais uncinata as stygoxenes.

\section{Clitellata of Iceland, an updated species list}

In Table 4, >90 taxa of Clitellata reported from Iceland to date are listed. The exact number of species is not yet known, considering that several taxa are species complexes. The present study has added eight binominal species new for Iceland, plus one unidentified Marionina sp. that may be new to science, and the small unidentified Chaetogaster sp., which if not a new species is possibly C. langi. Cernosvitoviella and Pristina are genera that have not been reported from Iceland before.

\section{Barcodes and species identification}

This study shows that when traditional (COI) barcoding fails due to DNA degradation, at least part of the material may be identified by targeting a shorter gene fragment (i.e., another barcode). The problem is to decide how short a barcode can be and still be species-specific enough for secure species identification. In theory, when degraded DNA is fragmented into ever-smaller pieces, the smaller the target sequence selected the higher the yield of successful sequences, but at the cost of less genetic information for distinguishing species. In our case, the longer of the two $16 \mathrm{~S}$ fragments ( $320 \mathrm{bp}$ ), produced significantly more sequences than COI (46 compared to 3), and revealed enough genetic variation to separate closely related species (Figure 2). For some of our taxa, however, species separation was based on only one or a few substitutions in the $16 \mathrm{~S}$ fragment. It is therefore important to note that we refer to these similar $16 \mathrm{~S}$ sequences as belonging to separate species, on the basis of other genetic information of other individuals of the same species, mainly from the more variable markers ITS (Internal Transcribed Spacer region) and COI (Erséus and Klinth, unpubl.). To be able to use a short gene fragment such as our 320-bp 16S to identify species it is clear that a large library with multiple sequences from all potential species, representing both inter- and intraspecific variability, is required.

Concerning the 70-bp 16S barcode, we surprisingly found that it did not produce more sequences than the 320-bp one, given the degraded DNA. Instead, it produced fewer successful barcodes. A likely explanation for this is sub-optimal binding of the primers, either due to the annealing temperature, or nucleotide variations in the primer-binding site (also indicated by a lack of bands in the post-PCR electrophoresis gel). The primers were originally designed for earthworms (Bienert et al. 2012), and in the present study they generally worked better for Lumbricidae than for the other families (Table 3), for which modified primers may be needed. It is possible that this very short $16 \mathrm{~S}$ partition does not contain enough variation to delimit all closely related species of Clitellata, and yet it proved variable enough to distinguish all the 17 successfully sequenced specimens in our current material from each other (Figure 3).

We had problems with contamination in eight of our specimens; their $16 \mathrm{~S}$ sequences ( $320 \mathrm{bp}$ ) did not match the species revealed by the morphology of the vouchers. In most cases we could attribute this to cross-contamination between samples, or possibly from the extraction lab. There were also some cases where the resulting sequences were those of human or bacterial DNA, but they were directly excluded from the counts of barcoded worms.

The integration of molecular and morphological data is particularly important in the delimitation of clitellate species (e.g., Martinsson et al. 2013; Klinth et al. 2017a). However, using DNA barcoding alone as a reliable shortcut to actual species identification has its pros and cons. In theory, clitellate barcoding is near to perfect when all species have been properly delimited. Moreover, it has the advantages of handling all life stages and even extra-organismal DNA (e.g., DNA from mucus left behind by tunnelling earthworms), and it separates cryptic species. On the other hand, this study has shown that problems occur in practice. We studied samples that suffered from 
Table 4. Updated checklist of clitellate species from Iceland. Previously recorded species from Iceland are presented together with the reference paper.

\begin{tabular}{|c|c|}
\hline Species sorted by family & References \\
\hline \multicolumn{2}{|l|}{ Enchytraeidae } \\
\hline Achaeta unibulba Graefe, Dózsa-Farkas \& Christensen 2005 & Graefe et al. 2005 \\
\hline Bryodrilus parvus Nurminen, 1970 & Nurminen 1973 \\
\hline Buchholzia appendiculata (Buchholz, 1862) & Christensen 1962; Nurminen 1973 \\
\hline Cernosvitoviella aggtelekiensis Dózsa-Farkas, 1970 & This study (new record) \\
\hline Cernosvitoviella cf. minor Dózsa-Farkas, 1990 (one in a species complex) & This study (new record) \\
\hline Cernosvitoviella pusilla Nurminen, 1973 & This study (new record) \\
\hline $\begin{array}{l}\text { Claparedrilus semifuscoides Klinth, Rota \& Erséus, } 2017 \\
\text { (previously reported as L. semifuscus) }\end{array}$ & Christensen 1962; Erséus 1976 \\
\hline $\begin{array}{l}\text { Cognettia glandulosa (Michaelsen, 1888) previous records could have been } C \text {. } \\
\text { glandulosa or } C \text {. varisetosa (see Martinsson, Rota \& Erséus, 2015a) }\end{array}$ & Christensen 1962; Nurminen 1973 \\
\hline $\begin{array}{l}\text { Cognettia sphagnetorum (Vejdovský, 1877) previous records could have been } \\
\text { C. chalupskyi, C. chlorophila, C. pseudosphagnetorum or C. sphagnetorum (see } \\
\text { Martinsson, Rota \& Erséus, 2015b) }\end{array}$ & Christensen 1962; Nurminen 1973 \\
\hline $\begin{array}{l}\text { Cognettia varisetosa (Martinsson, Rota \& Erséus, 2015a) } \\
\text { (previously a part of C. glandulosa) }\end{array}$ & This study (new record) \\
\hline Enchytraeus albidus Henle, 1837 & Christensen 1962; Erséus 1976 \\
\hline Enchytraeus buchholzi Vejdovský, 1879 (species complex) & $\begin{array}{l}\text { Christensen 1962; Nurminen 1973; two species } \\
\text { found in this study }\end{array}$ \\
\hline Enchytraeus coronatus Nielsen \& Christensen, 1959 & Christensen 1962 \\
\hline Enchytraeus minutus Nielsen \& Christensen, 1961 & Nurminen 1973 \\
\hline Enchytraeus norvegicus Abrahamsen, 1969 & Nurminen 1973 \\
\hline Fridericia bisetosa (Levinsen, 1884) & Christensen 1962; Nurminen 1973 \\
\hline Fridericia bulboides Nielsen \& Christensen, 1959 & Christensen 1962; Nurminen 1973 \\
\hline Fridericia bulbosa (Rosa, 1887) & Christensen 1962; Nurminen 1973 \\
\hline Fridericia callosa (Eisen, 1878) & Christensen 1962 \\
\hline Fridericia dura (Eisen, 1879) & This study (new record) \\
\hline Fridericia galba (Hoffmeister, 1843) & Christensen 1962; Nurminen 1973 \\
\hline Fridericia leydigi (Vejdovský, 1877) & Nurminen 1973 \\
\hline Friderica maculata Issel, 1905 & Christensen 1962 \\
\hline Fridericia perrieri (Vejdovsky) & Christensen 1962 \\
\hline Fridericia ratzeli (Eisen, 1872) & Christensen 1962; Nurminen 1973 \\
\hline Fridericia striata (Levinsen, 1884) & Christensen 1962 \\
\hline Grania postclitellochaeta (Knöllner, 1935) & Rota \& Erséus 2003 \\
\hline Henlea glandulifera Nurminen, 1970 & Nurminen 1973 \\
\hline Henlea nasuta (Eisen, 1878) & Christensen 1962 \\
\hline Henlea perpusilla Friend, 1911 & Christensen 1962; Nurminen 1973; this study \\
\hline Henlea ventriculosa (Udekem, 1854) & Christensen 1962; Nurminen 1973 \\
\hline Lumbricillus arenarius (Michaelsen, 1889) & Christensen 1962 , this study \\
\hline Lumbricillus lineatus (Müller, 1774) & Christensen 1962; Erséus 1976 \\
\hline Lumbricillus macrothecatus Erséus, 1976 & Erséus 1976 \\
\hline Lumbricillus pagenstecheri (Ratzel, 1869) & Christensen 1962; Erséus 1976 \\
\hline Lumbricillus pumilio Stephenson, 1932 & Erséus 1976 \\
\hline Lumbricillus reynoldsoni Backlund, 1948 & Christensen 1962 \\
\hline Lumbricillus rivalis Levinsen, 1883 emend. Ditlevsen, 1904 & Christensen 1962 \\
\hline
\end{tabular}


Table 4. Continued.

\begin{tabular}{|c|c|}
\hline Species sorted by family & References \\
\hline Lumbricillus scoticus Elmhirst \& Stephenson, 1926 & Christensen 1962; Erséus 1976 \\
\hline Lumbricillus viridis (Stephenson, 1911) & Christensen 1962; Erséus 1976 \\
\hline Marionina argentea (Michaelsen, 1889) (species complex) & Nurminen 1973; one species found in this study \\
\hline Marionina communis Nielsen \& Christensen, 1959 & Christensen 1962; Nurminen 1973 \\
\hline Marionina spicula (Leuckart, 1847) & Christensen 1962; Erséus 1976 \\
\hline Marionina sp. & This study (unidentified/new species?) \\
\hline Mesenchytraeus cf. armatus (Levinsen, 1884) (one in a species complex) & This study (new record) \\
\hline Mesenchytraeus flavus (Levinsen, 1884) & Christensen 1962; Nurminen 1973 \\
\hline \multicolumn{2}{|l|}{ Hirudinea } \\
\hline Callobdella nodulifera Malm, 1863 & Bruun 1938a \\
\hline Glossiphonia complanata (Linnaeus, 1758) & Bruun 1938b; Lindegaard 1979 \\
\hline Helobdella stagnalis (Linnaeus, 1758) & Bruun 1938b; Lindegaard 1979 \\
\hline Heptacyclus scorpii (Malm, 1863) & Bruun 1938a \\
\hline Johanssonia arctica (Johansson, 1899) & Perdiguero-Alonso et al. 2008 \\
\hline Oceanobdella microstoma (Johansson, 1896) & Bruun 1938a \\
\hline Oxytonostoma typica Malm, 1863 & Bruun 1938a \\
\hline Platybdella anarrhichae (Diesing, 1859) & Bruun 1938a \\
\hline Pontobdella muricata (Linnaeus, 1758) & Bruun 1938a \\
\hline Theromyzon garjaewi (Livanow, 1903) valid species? & Bruun $1938 b$ \\
\hline Theromyzon maculosum (Rathke, 1862) valid species? & Fjeldså \& Raddum 1973 \\
\hline Theromyzon tessulatum (Müller, 1774) & Bruun 1938b; Lindegaard 1979 \\
\hline \multicolumn{2}{|l|}{ Lumbricidae } \\
\hline Aporrectodea caliginosa (Savigny, 1826) & Backlund 1949; Lindroth et al. 1973; this study \\
\hline Aporrectodae rosea (Savigny, 1826) & Backlund 1949; Lindroth et al. 1973 \\
\hline $\begin{array}{l}\text { Bimastos rubidus s. lat. } \\
\text { (reported as Dendrodrilus rubidus (Savigny, 1826), Dendrodrilus subrubicundus } \\
\text { (Eisen, 1874), and Dendrodrilus tenuis (Eisen, 1874)) }\end{array}$ & Backlund 1949; Lindroth et al. 1973; this study \\
\hline Dendrobaena octaedra (Savigny, 1826) & Backlund 1949; Lindroth et al. 1973; this study \\
\hline Eisenia foetida (Savigny, 1826) & Backlund 1949 \\
\hline Eiseniella tetraedra (Savigny, 1826) & $\begin{array}{l}\text { Backlund 1949; Lindroth et al. 1973; Lindegaard } \\
\text { 1979; this study }\end{array}$ \\
\hline Lumbricus castaneus (Savigny, 1826) & Backlund 1949; Lindroth et al. 1973 \\
\hline Lumbricus rubellus Hoffmeister, 1843 & Backlund 1949; Lindroth et al. 1973 \\
\hline Lumbricus terrestris Linnaeus, 1758 & Backlund 1949; Lindroth et al. 1973 \\
\hline Octolasium cyaneum (Savigny, 1826) & Backlund 1949 \\
\hline \multicolumn{2}{|l|}{ Lumbriculidae } \\
\hline Lumbriculus variegatus (Müller, 1774) & Hrabě 1952; Lindegaard 1979 \\
\hline Stylodrilus heringianus Claparède, 1862 & Hrabě 1952; Lindegaard 1979 \\
\hline \multicolumn{2}{|l|}{ Naididae } \\
\hline Aktedrilus arcticus (Erséus, 1978) & Erséus 1978 \\
\hline Aulodrilus limnobius Bretscher, 1899 & Hrabě 1952 \\
\hline Aulodrilus pluriseta (Piguet, 1906) & Hrabě 1952 \\
\hline
\end{tabular}


Table 4. Continued.

\begin{tabular}{|c|c|}
\hline Species sorted by family & References \\
\hline Baltidrilus costatus (Claparède, 1863) & Erséus 1976 \\
\hline Chaetogaster diaphanus (Gruithuisen, 1828) & Hrabě 1952; Lindegaard 1979 \\
\hline Chaetogaster cf. diastrophus (Gruithuisen, 1828) (one in a species complex) & This study (new record) \\
\hline Chaetogaster langi Bretscher, 1896 & Hrabě 1952; Lindegaard 1979 \\
\hline Chaetogaster sp. (possibly Ch. langi?) & This study (Ch. langi found again?) \\
\hline Christerius litoralis (Erséus, 1976) & Erséus 1976 \\
\hline Clitellio arenarius (Müller, 1776) & Hrabě 1952; Brinkhurst 1963; Erséus 1976 \\
\hline Nais communis Piguet, 1906 & Hrabě 1952; Lindegaard 1979 \\
\hline Nais communis/variabilis species complex, morphotype A3 (see Envall et al. 2012) & This study \\
\hline Nais elinguis Müller, 1773 & $\begin{array}{l}\text { Hrabě 1952; Erséus 1976; Lindegaard 1979; this } \\
\text { study }\end{array}$ \\
\hline Nais variabilis Piguet, 1906 & Hrabě 1952 \\
\hline Paranais litoralis (Müller, 1784) & Erséus 1976 \\
\hline Pristina foreli (Piguet, 1907) & This study (new record) \\
\hline Specaria josinae (Vejdovský, 1883) & Hrabě 1952 \\
\hline Spirosperma ferox (Eisen, 1879) & Hrabě 1952; Lindegaard 1979 \\
\hline Stylaria lacustris (Linnaeus, 1767) & Hrabě 1952 \\
\hline Thalassodrilus firmus (Erséus, 1979) & Erséus 1979 \\
\hline Tubifex tubifex (Müller, 1774) (species complex) & $\begin{array}{l}\text { Hrabě 1952; Lindegaard 1979; one species found } \\
\text { in this study }\end{array}$ \\
\hline Tubificoides benedii (Udekem, 1855) & Brinkhurst 1963; Erséus 1976 \\
\hline Tubificoides kozloffi Baker, 1983 & Helgason \& Erséus 1987 \\
\hline Uncinais uncinata (Ørsted, 1842) & Hrabě 1952; Lindegaard 1979; this study \\
\hline
\end{tabular}

DNA deterioration, which considerably reduced the number of identified specimens. We also found evidence of DNA contamination, which would have led to the wrong conclusions, had we not compared the morphology of a specimen with the barcode sequence obtained. The conclusion is that any samples to be used for DNA analysis must be handled properly, e.g., kept at low temperature, conserved in high concentration of ethanol or DNA preserving buffers, and minimizing storage time. By doing so, the risk of low sequencing success as well as obtaining erroneous identifications due to contamination will be considerably reduced.

\section{ACKNOWLEDGEMENTS}

AKK received funding from the Icelandic Research Fund (RANNÍS), grant nr. 141863-051. The map used for Figure 1 reproduced and modified with permission from d-maps.com (URL: https://d-maps.com/carte.php?num car=21661\&lang=en).

\section{REFERENCES}

Achurra A, Rodriguez P. 2008. Biodiversity of groundwater oligochaetes from a karst unit in northern Iberian Peninsula: Ranking subterranean sites for conservation management. Hydrobiologia 605: 159-171. doi: 10.1007/s10750-008-9331-2

ArifIA, Khan HA, Al Sadoon, M, Shobrak M. 2011. Limited efficiency of universal mini-barcode primers for DNA amplification from desert reptiles, birds and mammals. Genetics and Molecular Research, 10(4): 3559-3564. doi: 10.4238/2011.October.31.3

Backlund HO. 1949. Oligochaeta 1. Lumbricidae. The Zoology of Iceland 2, Part 20a: 1-15.

Bely AE, Wray GA. 2004. Molecular phylogeny of naidid worms (Annelida: Clitellata) based on cytochrome oxidase I. Molecular phylogenetics and evolution, 30(1): 50-63. doi: 10.1016/S10557903(03)00180-5

Bienert F, De Danieli S, Miquel C, Coissac E, Poillot C, Brun JJ, Taberlet P. 2012. Tracking earthworm communities from soil DNA. Molecular Ecology 21: 2017-2030. doi: 10.1111/j.1365294X.2011.05407.x

Bojková J, Schenková J, Horsák M, Hájek M. 2011. Species richness and composition patterns of clitellate (Annelida) assemblages in the treeless spring fens: the effect of water chemistry and substrate. Hydrobiologia 667: 159-171. doi: 10.1007/s10750-0110634-3

Brinkhurst RO. 1963. Notes on the brackish-water and marine species 
of Tubificidae [Annelida, Oligochaeta]. Journal of the Marine Biological Association of the United Kingdom 43(3): 709-715. doi: 10.1017/S0025315400025637

Bruun AF. 1938a. Marine Hirudinea. The Zoology of Iceland 2, Part 21: $1-5$.

Bruun AF. 1938b. Freshwater Hirudinea. The Zoology of Iceland 2, Part 22: 1-4.

Černosvitov L. 1929. Communication préliminaire sur les Oligochètes récoltés par MP Remy pendant la croisière arctique effectuée par le» Pourquoi-Pas?» en 1926 sous la direction du Dr. J.-B. Charcot. Bulletin du Muséum National d'Histoire Naturelle, Paris 2(1): 144-149.

Černosvitov L. 1931. Sur quelques Oligochetes de la Region Arctique et des lles Faer-oer. Annales des sciences naturelles, Zoologie 14(10): $65-110$.

Černosvitov L. 1936. Oligochaeta from Iceland and Grimsey Island. The Annals and Magazine of Natural History 18(10): 224-226. doi: 10.1080/00222933608655186

Christensen B. 1962. Oligochaeta 3. Enchytraeidae. The Zoology of Iceland 2, Part 20c: 1-11.

Deagle BE, Jarman SN, Coissac E, Pompanon F, Taberlet P. 2014. DNA metabarcoding and the cytochrome $\mathrm{c}$ oxidase subunit I marker: not a perfect match. Biology letters, 10(9): 20140562. doi: $10.1098 / \mathrm{rsbl} .2014 .0562$

Dózsa-Farkas K. 2019. Enchytraeids of Hungary (Annelida: Clitellata, Enchytraeidae). Pedozoologica Hungarica 7: 1-226. (Eötvös University Press, Budapest).

Drummond AJ, Ashton B, Buxton S, Cheung M, Cooper A, Duran C, Field M, Heled J, Kearse M, Markowitz S, Moir R, Stones-Havas S, Sturrock S, Thierer T, Wilson A. 2011 Geneious v5.5, Available from http://www.geneious.com

Envall I, Gustavsson LM, Erséus C. 2012. Genetic and chaetal variation in Nais worms (Annelida, Clitellata, Naididae). Zoological Journal of the Linnean Society 165(3): 495-520. doi: 10.1111/j.1096-3642.2012.00828.x

Erséus C. 1976. Littoral Oligochaeta (Annelida) from Eyjafjörôur, North Coast of Iceland. Zoologica Scripta 5: 5-11. doi: 10.1111/ j.1463-6409.1976.tb00677.x

Erséus C. 1978. Two New Species of the Little-known Genus Bacescuella Hrabě (Oligochaeta, Tubificidae) from the North Atlantic 1. Zoologica Scripta 7(1-4): 263-267. doi: 10.1111/j.14636409.1978.tb00609.x

Erséus C. 1979. Taxonomic Revision of the Marine Genus Phallodrilus Pierantoni (Oligochaeta, Tubificidae), with Descriptions of Thirteen New Species 1. Zoologica Scripta 8(1-4): 187-208. doi: 10.1111/j.1463-6409.1979.tb00631.x

Erséus C. 1994. The Oligochaeta. In: Blake J.A. \& Hilbig B. (Eds.), Taxonomic Atlas of the Benthic Fauna of the Santa Maria Basin and Western Santa Barbara Channel, Volume 4, Oligochaeta and Polychaeta: Phyllodocida (Phyllodocidae to Paralacydoniidae). Santa Barbara Museum of Natural History, Santa Barbara California. pp 5-38.

Fjeldså J, Raddum GG. 1973. Three limnic invertebrate species new to Iceland, found in Mývatn in 1969. Náttúrufrædingurinn 43: $103-113$.

Folmer O, Black M, Hoeh W, Lutz R, Vrijenhoek R. 1994. DNA primers for amplification of mitochondrial cytochrome $\mathrm{c}$ oxidase subunit I from diverse metazoan invertebrates. Mol Mar Biol Biotechnol 3: 294-299.
Giani N, Sambugar B, Rodriguez P, Martínez-Ansemil E. 2001. Oligochaetes in southern European groundwater: new records and overview. Hydrobiologia 463: 65-74. doi: 10.1023/A:1013183003707

Giani N, Sambugar B, Rodriguez P, Martin P, Schmelz RM. 2011. The groundwater oligochaetes (Annelida, Clitellata) of Slovenia. Subterranean Biology 9: 85-102. doi: 10.3897/subtbiol.9.2512

Govoni DP, Kristjánsson BK, Ólafsson JS. 2018. Spring type influences invertebrate communities at cold spring sources. Hydrobiologia 808: 315-325. doi: 10.1007/s10750-017-3434-6

Graefe U, Dozsa-Farkas K, Christensen B. 2005. Achaeta unibulba sp. n., a widespread European species (Oligochaeta, Enchytraeidae). In Proceedings of the Estonian Academy of Sciences, Biology, Ecology 54(4): 271-278.

Hajibabaei M, Smith MA, Janzen DH, Rodriguez JJ, Whitfield JB, Hebert PD. 2006. A minimalist barcode can identify a specimen whose DNA is degraded. Molecular Ecology Notes 6(4): 959964. doi: 10.1111/j.1471-8286.2006.01470.x

Helgason GV, Erséus C. 1987. Three new species of Tubificoides (Oligochaeta, Tubificidae) from the North-West Atlantic and notes on geographic variation in the circumpolar T. kozloffi. Sarsia 72(2): 159-169. doi: 10.1080/00364827.1987.10419713

Hebert PDN, Cywinska A, Ball SL, DeWaard JR. 2003. Biological identifications through DNA barcodes. Proceedings of the Royal Society of London B, Biological Sciences 270: 313-321. doi: 10.1098/rspb.2002.2218

Hebert PD, Penton EH, Burns JM, Janzen DH, Hallwachs W. 2004. Ten species in one: DNA barcoding reveals cryptic species in the neotropical skipper butterfly Astraptes fulgerator. Proceedings of the National Academy of Sciences 101(41): 14812-14817. doi: 10.1073/pnas.0406166101

Hrabě S. 1952. Oligochaeta 2. Limicola. The Zoology of Iceland 2, Part 20b: 1-10.

Klinth MJ, Martinsson S, Erséus C. 2017a. Phylogeny and species delimitation of North European Lumbricillus (Clitellata, Enchytraeidae). Zoologica Scripta 46: 96-110. doi: 10.1111/ zsc. 12187

Klinth MJ, Rota E, Erséus C. 2017b. Taxonomy of North European Lumbricillus (Clitellata, Enchytraeidae). ZooKeys 703: 15-96. doi: 10.3897/zookeys.703.13385

Kreiling A-K, Ólafsson JS, Pálsson S, Kristjánsson BK. 2018. Chironomidae fauna of springs in Iceland-assessing the ecological relevance behind Tuxen's spring classification. Journal of Limnology 77: 145-154. doi: 10.4081/jlimnol.2018.1754

Lento J, Morin A. 2014. Filling the gaps in stream size spectra: using electroshocking to collect large macroinvertebrates. Hydrobiologia 732: 1-17. doi: 10.1007/s10750-014-1840-6

Leray M, Yang JY, Meyer CP, Mills SC, Agudelo N, Ranwez V, Boehm JT, Machida RJ. 2013. A new versatile primer set targeting a short fragment of the mitochondrial COI region for metabarcoding metazoan diversity: application for characterizing coral reef fish gut contents. Frontiers in zoology, 10(1): 34. doi: 10.1186/1742-9994-10-34

Lindegaard C. 1979. The Invertebrate Fauna of Lake Mývatn, Iceland. Oikos 32: 151-161. doi: 10.2307/3544225

Lindroth CH, Andersson H, Bödvarsson H, Richter SH. 1973. Surtsey, Iceland. The development of a new fauna, 1963 1970. Terrestrial invertebrates. Entomologica Scandinavica. Supplementum 5. 
Martin P, Schmelz RM, Dole-Olivier M-J. 2015. Groundwater oligochaetes (Annelida, Clitellata) from the Mercantour National Park (France), with the descriptions of one new genus and two new stygobiont species. Zoosystema 37(4): 551-569. doi: $10.5252 / \mathrm{z} 2015 \mathrm{n} 4 \mathrm{a} 2$

Martinsson S, Achurra A, Svensson M, Erséus C. 2013. Integrative taxonomy of the freshwater worm Rhyacodrilus falciformis s.l. (Clitellata: Naididae), with the description of a new species. Zoologica Scripta 42: 612-622. doi: 10.1111/zsc.12032

Martinsson S, Rota E, Erseus C. 2015a. On the identity of Chamaedrilus glandulosus (Michaelsen, 1888)(Clitellata, Enchytraeidae), with the description of a new species. ZooKeys 501: 1-14. doi: 10.3897/zookeys.501.9279

Martinsson S, Rota E, Erséus C. 2015b. Revision of Cognettia (Clitellata, Enchytraeidae): re-establishment of Chamaedrilus and description of cryptic species in the sphagnetorum complex. Systematics and Biodiversity, 13(3): 257-277. doi: 10.1080/14772000.2014.986555

Meusnier, I., Singer, G. A., Landry, J. F., Hickey, D. A., Hebert, P. D., \& Hajibabaei, M. 2008. A universal DNA mini-barcode for biodiversity analysis. BMC genomics, 9(1): 214. doi: 10.1186/1471-2164-9-214

Nielsen CO, Christensen B. 1959. The Enchytraeidae: critical revision and taxonomy of European species. Natura Jutlandica 8-9: 1-160.

Nurminen M. 1973. Enchytraeidae (Oligochaeta) of Iceland. In: Annales Zoologici Fennici. Societas Biologica Fennica Vanamo. pp. 412-413.

Perdiguero-Alonso D, Montero FE, Raga JA, Kostadinova A. 2008. Composition and structure of the parasite faunas of cod, Gadus morhua L. (Teleostei: Gadidae), in the North East Atlantic. Parasites \& vectors 1(1): 23. doi: 10.1186/1756-3305-1-23

Rota E, Erséus C. 2003. New records of Grania (Clitellata, Enchytraeidae) in the Northeast Atlantic (from Tromsø to the Canary Islands), with descriptions of seven new species. Sarsia: North Atlantic Marine Science 88(3): 210-243. doi: 10.1080/00364820310001615

Sambugar B, Giani N, Martínez-Ansemil E. 1999. Groundwater oligochaetes from Southern-Europé. Tubificidae with marine phyletic affinities: new data with description of a new species, review and consideration on their origin. Mémoires de Biospéologie 26: 107-116.

Schmelz RM, Collado R. 2010. A guide to European terrestrial and freshwater species of Enchytraeidae (Oligochaeta). Soil Organisms 82: 1-176.

Sims RW, Gerard BM. 1985. Earthworms: keys and notes for the identification and study of the species. Synopses of the British Fauna (New Series) 31: 1-171. (E. J. Brill/Dr. W. Backhuys, London)

Sjölin E, Erséus C, Källersjö M. 2005. Phylogeny of Tubificidae (Annelida, Clitellata) based on mitochondrial and nuclear sequence data. Molecular Phylogenetics and Evolution 35: 431-441. doi: 10.1016/j.ympev.2004.12.018

Timm T. 2009. A guide to the freshwater Oligochaeta and Polychaeta of Northern and Central Europe. Lauterbornia 66: $1-235$.

Vink CJ, Thomas SM, Paquin P, Hayashi CY, Hedin M. 2005. The effects of preservatives and temperatures on arachnid DNA. Invertebrate systematics 19(2): 99-104. doi: 10.1071/IS04039
Editorial responsibility: Torkild Bakken.

This article is open-access and distributed under the terms of the Creative Commons Attribution 4.0 International license. This permits all non-commercial use, distribution, and reproduction in any medium, provided the original work is properly cited.

(http://creativecommons.org/licenses/by/4.0/). 